\title{
Business Ethics in Greater China: An Introduction
}

\author{
Allan K. K. Chan \\ Po-Keung Ip \\ Kit-Chun Joanna Lam
}

This Special Issue attempts to focus on a theme that is broad and ambitious, but also timely and practically important. As the wordings of the theme reflect, our intention is to cover business ethics issues not just in the Chinese mainland, but also in Taiwan, Hong Kong, Macau, and perhaps other locations with substantial Chinese population. The choice of "Greater China" instead of China is intentional, in order to avoid too much constraints on political boundary of national definitions. It is well understood to most people that China is always referred to the People's Republic of China (PRC), or the Chinese mainland as understood by most Chinese people. Hong Kong and Macau, both having a colonial history, have become a Special Administrative Region (SAR) of the PRC in 1997 and 1999, respectively. Taiwan is special, but also Chinese populated. These Chinese people, and perhaps also many so-called overseas Chinese, could all be seen to be rooted under the broadly defined Chinese culture. We are therefore trying to stay away from the political national boundaries, but to look for academic research efforts amongst the Chinese population, the Chinese businesses, and their behaviors in relation to business ethics. The use of the term Greater China probably would dilute the political boundary and help achieve the academic purpose.

There is obviously a growing interest amongst researchers investigating issues of business ethics in the Greater China. A simple statistics from the Journal of Business Ethics, for example, shows that in the past decade (1998-2008 latest issue), there were a total of 90 articles with a national or cultural emphasis about China, including the Chinese mainland, Taiwan, and Hong Kong, and also comparative studies (both "within" comparison meaning comparative studies within the Greater China, and "between" comparison meaning comparative studies between Chinese people and those of other nations). As Table I indicates, ethical perception (30 out of 155 counts) and "between" comparison (Chinese with people of other nations) (28 counts) have been the most researched areas, followed by studies in guanxi (16 counts), ethical values (15 counts), and general business ethics (15 counts). The following topics have been published to some extent and they would seem to be areas of growing interest: work ethics (9 counts), corporate social responsibility (CSR) (9 counts), marketing ethics (9 counts), and ethical education (6 counts). In terms of locational coverage, mainland China has the most (70 counts), followed by Hong Kong (43 counts), Taiwan (33 counts), and China overall (9 counts).

Looking at this growing interest in business ethics issues in Greater China, two major observations need to be highlighted.

Firstly, although a wide coverage of topics has appeared, there is a lack of indigenous research approach, and the majority of researchers are either trained outside the Chinese mainland or adopted western traditional research methodologies to do comparative works. A second observation is a less academic one. Incidents which appear to be related to business ethics or human rights always attract media's or journalists' attention. For example, it is not uncommon to see statements such as "There are too many fake Chinese goods. Anything for a profit, that's today's China!" or "A political system without popular elections or an effective system of checks and balances has helped create a culture in which the Chinese are not accountable to each other" (The Wall Street Journal (Eastern edition), July 12, 2007, p. A15) in journalistic writing, which is imposing some kind of conclusive remarks, although 
obviously not research-based, to a large group of readers. Actually, as media reports are usually based on incidents or happenings, they are definitely factual, but they may or may not be readily generalized to a nation or the whole population of the ethnic group. This phenomenon is another reflection of the general public's growing interest about China, and her business ethics situation in particular. This could also be seen as another motivational factor to academic researchers in pursuing scientific research works on business ethics topics in Greater China. Research findings from serious researchers, with appropriate research methodologies, and media's coverage, would certainly help to present the true picture to the general public who are always interested in such issues.

The aim of this Special Issue, therefore, is to invite contributions that address major topics of business ethics in Greater China. Two criteria, namely, direct relevance to the theme and academic rigor, are used to select papers amongst an overwhelming number of submissions of good quality.

Among the 14 papers included in this collection, majority are based on samples from the Chinese mainland. Leung et al. for example, explored the moral intention of the migrant workers in the mainland. Basing on the works of Kohlberg (1969, 1981) and Rest et al. (2000), they tried to examine the relationship between moral reasoning and behavioral intention, and measured moral intention using four ethical scenarios. It was shown that the egoistic schema had a positive effect on their intention to act unethically while the legislative schema exerted a negative effect. Zhang et al. on the other hand, surveyed a sample of bank employees in eastern China on their whistleblowing decision making process. As incidents of organizational wrongdoing often cause unmeasurable damages of goodwill to the companies concerned, these scandals come to light mainly because of the actions of employees or ex-employees who believed that the wrongdoing should be stopped, and reported them to the authorities. In their study, Zhang et al. showed that in China, people's perception of their organizational ethical culture is a significant factor influencing their judgment of whistleblowing and the whistleblowing intention during their decision making process whether or not to blow the whistle. As remarked by the 
authors, the disclosure of unethical behavior is important as it can protect companies from expensive lawsuits, financial loss, and decreased morale. It is especially important for Chinese businesses as they are competing not just domestically but also in the international arenas.

Advertising issues are important, as one can imagine, in the Chinese consumer market of huge size. Fam et al. in their article addressing the advertising issues, focused on the advertising of potentially controversial products. China being part of the vast global market, the Chinese consumers of all ages are having a greater opportunity of exposure to different kinds of advertising including those of controversial products. Their study had a large sample of respondents from three major Chinese cities, with findings showing that for the advertising of alcohol, there appears to be little offence, but for more private products like condoms, there appears high level of offence.

Accounting practice is another growing industry in China. Unlike advertising, which is highly interactive with the consumers or message receivers, the accounting profession has a major concern on the group of practitioners who provide information that can facilitate better decision making in an organization, and they attest to information reported by organizations, thus affecting investors' confidence in these organizations. Recognizing the recent development of China's Ministry of Finance in announcing a set of new auditing and accounting standards which were revised according to International Financial Reporting Standards (IFRS) and the requirement of China's publicly listed companies to abide by IFRS since 2007, Lan et al. reported their survey with a large sample from six major Chinese cities on Chinese Accounting practitioners and students regarding their personal values and value types, adopting the Schwartz Values Survey Questionnaire (SVQ) (Schwartz, 1992). Again, this is an illustration of using an established instrument in a Chinese survey. Their findings showed that healthy and family security were ranked first and second, respectively, by both groups of accounting practitioners and students. Self-respect and honoring of parents and elders were ranked third and fourth by accounting practitioners, and the order is reversed for accounting students. Security was the highest ranked value type for both groups.
Over the past few years, the Chinese notion of guanxi has received considerable attention. In this Special Issue, two articles on guanxi are included. Although they are both exploring the Supervisorsubordinate (S-S) guanxi, they have different emphasis, and adopt different research approaches, quantitative and qualitative, respectively. Cheung et al. reported a study with a sample from manufacturing firms in eastern China. They extended the literature on S-S guanxi by demonstrating the mediating role of job satisfaction in the relationship between S-S guanxi and work outcomes. With quantitative testing of hypotheses, the findings showed that job satisfaction fully mediated the effects of S-S guanxi on participatory management and intention to leave, and partially mediated the relationship between S-S guanxi and organizational commitment. This investigation fills the gap in existing literature where insignificant result was found for the relationships between S-S guanxi and employee work outcomes. The findings of Cheung et al. is salient because job satisfaction highlights the affective responses of employees to their job, and that is essential for providing underlying motivations for positive employee outcomes. The second paper on guanxi by Han and Altman, adopting the Grounded Theory approach, looked at the S-S guanxi by exploring the perception of guanxi from both superior and subordinate perspectives in the Chinese mainland. By collecting and analyzing critical incidents from both supervisors and subordinates from northern China, the study reported that, on the positive side, guanxi comprises reciprocal exchange and perceived positive attributes, whereas its darker aspects include perceived unfairness and supervisor-targeted impression management.

Corporate Social Responsibility (CSR) and consumers' awareness of it are gaining popularity in recent years. $Z u$ and Song, for example, reported a survey done in mainland China to investigate how Chinese executives and managers perceive and interpret CSR, to what extent firms' productive characteristics influence managers' attitudes toward their CSR rating, and whether their values in favor of CSR are positively correlated to firms' economic performance. Their survey covers managers from Northern, Southeast, and West China. Their findings point to an understanding that the true determination of CSR orientation is still firms' economic 
features, and managers' interpretations of CSR activities could be seen in terms of economic incentives. Since acceptance of CSR obviously appears to do no harm to economic performance, or even associate with good increase of sales, the more better-off a firm is, the more likely its manager is to get involved in CSR activities. On the other hand, while recognizing majority of published studies have been highlighting the role of CSR in the American and European consumers' evaluation of companies and their decisions to purchase their products, Ramasamy and Yeung reported their study in this Special Issue comparing the Chinese mainland, Hong Kong, and Malaysia, trying to offer an Asian perspective on consumers' perception of CSR. Their study was based on an instrument developed by Maignan (2001), and showed that Asian consumers are more supportive of socially responsible activities of firms as compared to their western counterparts. Their results also confirm that Asian consumers are able to differentiate between the economic, legal, ethical, and philanthropic responsibilities of businesses, following the Carroll's CSR pyramid (Carroll, 1979). Of course consumer perception of business' responsibilities has to be transferred to actual CSR strategy which might vary across countries. In the Greater China, it would be expected that the CSR strategies of firms in the mainland might differ from those of Hong Kong and Taiwan firms. To reflect the growing concern, we have included another paper on CSR, by Shen and Chang, who focused their attention on Taiwan firms (CSR and non-CSR firms) by examining the effect of CSR on their financial performance. Adopting five matching methods to fix the characteristics of the two groups of firms in order to correct for sample selection bias, the study concluded that, although the estimated results are mixed, adopting the CSR at the very least does not deteriorate the performance of firms. They came to a remark which says: ambition and conscience do not conflict with each other.

A further study carried out in Taiwan relates to ethically questionable behavior in sales representatives. Hsu et al. reported their study with empirical works being done with the Taiwan pharmaceutical industry. Using a $2 \times 2 \times 2 \times 2$ experimental design, their results suggest that a sales representative of pharmaceutical products in a loss frame (compared with a gain frame), in a high commission structure (compared with a low commission structure), in loose behavior control (compared with strict behavior control), and in a low perception of marketing norm (compared with a high perception of marketing norm) is more likely affected by heuristic biases and will make an ethically questionable choice. This study is useful in providing managers with insights in the puzzle of avoiding ethically questionable behavior in the sales force. The four variables, namely, frame pattern, commission structure, behavioral control, and marketing norm perceptions, are highlighted.

Two articles are based on Hong Kong samples. The first one, by Siu and Lam, compared the ethical perceptions of managers and non-managers (including professionals and other occupations). The authors adopted an instrument with 28 vignettes to address a variety of ethically questionable situations and ethical issues of particular concerns in Hong Kong. Factor analysis and regression analysis were adopted in the data analyses. The study reveals that managers tend to possess deontological views that are more ethical than that found in other occupations. The gap between managers and professionals in perceiving unethical behavior is narrower as compared to other occupations. The acceptability of unethical behaviors tends to decline with income. There are also indications that people working in non-profit organizations tend to have higher ethical standards. The second article by Wan et al. addresses a paradox in Chinese consumption (again using a Hong Kong sample), where they have a simultaneous preference for two contrasting types of products: adoption of luxurious and branded products, and buying counterfeited products. Using structural equation modeling and path analysis, the findings suggest that face consciousness increased materialism and risk aversion, thereby producing a favorable deontological judgment of counterfeited products (in their study, pirated CDs). Face consciousness also has a direct effect on the amount of social benefits perceived in pirated CDs. Both favorable deontological judgment and perceived social benefits contributed to a strong intention to buy pirated CDs. With such explanation, the buying of pirated CDs appears to be a cultural phenomenon, and therefore law enforcement, however strict it can be, would not be sufficient to solve the problem. 
The solution may come down to the fundamental level, which is consumer education.

This Special Issue is concluded with two articles addressing the theme in a comparative or more general manner. Tan and Chow reported their study advocating an analytical framework which isolates the role of cultural and national differences in order to test their relationship to individual level variables. With the framework, they test competing hypotheses based on cultural and national contexts by comparing Chinese and American respondents, and a "bridging group" of Chinese Americans. Their findings indicate that the two ethnic Chinese groups shared most of the cultural values, and they are significantly different from the Caucasian samples. Ip's article, taking the approach of normative analysis and framework setting, attempts to develop a business ethics (identify the challenges of developing a business ethics) in response to current CSR development in China. Against China's cultural and ideological backdrop, the article constructs the profile of a prospective business ethics that is workable and reasonable for China by articulating its formal constraints and substantive components.

We hope that through the collection of articles in the Special Issue some light is shed on some corners of the vast terrain of business ethics in Greater China.

\section{Appendix 1}

Articles related to business ethics in Greater China published in Journal of Business Ethics since 1998

Ahmed, M. M., K. Y. Chung and J. W. Eichenseher: 2003, 'Business Students' Perception of Ethics and Moral Judgment: A Cross-Cultural Study', Journal of Business Ethics 43, 89-102.

Ang, S. H. and S. M. Leong: 2000, 'Out of the Mouths of Babes: Business Ethics and Youths in Asia', Journal of Business Ethics 28, 129-144.

$\mathrm{Au}$, A. K. M. and D. S. N. Wong: 2000, 'The Impact of Guanxi on the Ethical Decision-Making Process of Auditors - An Exploratory Study on Chinese CPAs in Hong Kong', Journal of Business Ethics 28, 87-93.

Baker, H. K. and E. T. Veit: 1998, 'A Comparison of Ethics of Investment Professionals: North
America Versus Pacific Rim Nations', Journal of Business Ethics 17, 917-937.

Bernardi, R. A.: 2006, 'Associations Between Hofstede's Cultural Constructs and Social Desirability Response Bias', Journal of Business Ethics 65, 43-53.

Brand, V. and A. Slater: 2003, 'Using a Qualitative Approach to Gain Insights into the Business Ethics Experiences of Australian Managers in China', Journal of Business Ethics 45, 167-182.

Chan, A., S. Wong and P. Leung: 1998, 'Ethical Beliefs of Chinese Consumers in Hong Kong', Journal of Business Ethics 17, 1163-1170.

Chan, R. Y. K., L. T. W. Cheng and R. W. F. Szeto: 2002, 'The Dynamics of Guanxi and Ethics for Chinese Executives', Journal of Business Ethics 41, 327-336.

Chang, C. J. and S. H. Yen: 2007, 'The Effects of Moral Development and Adverse Selection Conditions on Managers' Project Continuance Decisions: A Study in the Pacific-Rim Region', Journal of Business Ethics 76, 347-360.

Chen, A. W. and J. M. C. Liu: 1998, 'Agency Practitioners' Perceptions of Professional Ethics in Taiwan', Journal of Business Ethics 17, 15-23.

Chen, T. T. Y.: 2001, 'Ethics Control Mechanisms: A Comparative Observation of Hong Kong Companies', Journal of Business Ethics 30, 391-400.

Chen, Y. S.: 2008, 'The Positive Effect of Green Intellectual Capital on Competitive Advantages of Firms', Journal of Business Ethics 77, 271-286.

Chen, Y. S., S. B. Lai and C. T. Wen: 2006, 'The Influence of Green Innovation Performance on Corporate Advantage in Taiwan', Journal of Business Ethics 67, 331-339.

Cherry, J.: 2006, 'The Impact of Normative Influence and Locus of Control on Ethical Judgments and Intentions: A Cross-Cultural Comparison', Journal of Business Ethics 68, 113-132.

Cherry, J., M. Lee and C. S. Chien: 2003, 'A Cross-Cultural Application of a Theoretical Model of Business Ethics: Bridging the Gap Between Theory and Data', Journal of Business Ethics 44, 359376.

Cheung, C. K. and A. C. F. Chan: 2005, 'Philosophical Foundations of Eminent Hong Kong Chinese CEOs' Leadership', Journal of Business Ethics 60, 47-62.

Cheung, T. S. and A. Y. C. King: 2004, 'Righteousness and Profitableness: The Moral Choices of 
Contemporary Confucian Entrepreneurs', Journal of Business Ethics 54, 245-260.

Chiou, J. S., C. Y. Huang and H. H. Lee: 2005, 'The Antecedents of Music Piracy Attitudes and Intentions', Journal of Business Ethics 57, 161-174.

Chiou, J. S. and L. Y. Pan: 2008, 'The Impact of Social Darwinism Perception, Status Anxiety, Perceived Trust of People, and Cultural Orientation on Consumer Ethical Beliefs', Journal of Business Ethics 78, 487-502.

Chiu, R. K.: 2003, 'Ethical Judgment and Whistle Blowing Intention: Examining the Moderating Role of Locus of Control', Journal of Business Ethics 43, 65-74.

Cui, C. C., V. Mitchell, B. B. Schlegelmilch and B. Cornwell: 2005, 'Measuring Consumers' Ethical Position in Austria, Britain, Brunei, Hong Kong, and USA', Journal of Business Ethics 62, 57-71.

Douglas, P. C. and B. Wier: 2005, 'Cultural and Ethical Effects in Budgeting Systems: A Comparison of US and Chinese Managers', Journal of Business Ethics 60, 159-174.

Du, L. Z. and T. L. P. Tang: 2005, 'Measurement Invariance Across Gender and Major: The Love of Money Among University Students in People's Republic of China', Journal of Business Ethics 59, 281-293.

Dunfee, T. W. and D. E. Warren: 2001, 'Is Guanxi Ethical? A Normative Analysis of Doing Business in China', Journal of Business Ethics 32, 191-204.

Ebrahimi, B. P., J. A. Petrick and S. A. Young: 2005, 'Managerial Role Motivation and Role-Related Ethical Orientation in Hong Kong', Journal of Business Ethics 60, 29-45.

Egels-Zanden, N.: 2007, 'Suppliers' Compliance with MNCs' Codes of Conduct: Behind the Scenes at Chinese Toy Suppliers', Journal of Business Ethics 75, 45-62.

Enderle, G.: 2001, 'Integrating the Ethical Dimension into the Analytical Framework for the Reform of State-Owned Enterprises in China's Socialist Market Economy: A Proposal', Journal of Business Ethics 30, 261-275.

Etheredge, J. M.: 1999, 'The Perceived Role of Ethics and Social Responsibility: An Alternative Scale Structure', Journal of Business Ethics 18, 51-64.

Fan, Y.: 2002, 'Ganxi's Consequences: Personal Gains at Social Cost', Journal of Business Ethics 38, 371-380.
Firth, M., P. L. L. Mo and R. M. K. Wong: 2005, 'Financial Statement Frauds and Auditor Sanctions: An Analysis of Enforcement Actions in China', Journal of Business Ethics 62, 367-381.

Fox, J. B., J. M. Donohue and J. Wu: 2005, 'Beyond the Image of Foreign Direct Investment in China: Where Ethics Meets Public Relations', Journal of Business Ethics 56, 317-324.

Fryxell, G. E. and C. W. H. Lo: 2003, 'The Influence of Environmental Knowledge and Values on Managerial Behaviors on Behalf of the Environment: An Empirical Examination of Managers in China', Journal of Business Ethics 46, 45-69.

Gul, F. A., A. Y. Ng, M. Yew and J. W. Tong: 2003, 'Chinese Auditors' Ethical Behavior in an Audit Conflict Situation', Journal of Business Ethics 42, 379-392.

Hall, J., S. Matos, and C. H. Langford: 2008, 'Social Exclusion and Transgenic Technology: The Case of Brazilian Agriculture', Journal of Business Ethics 77, 45-63.

Harvey, B.: 1999, “Graceful Merchants": A Contemporary View of Chinese Business Ethics', Journal of Business Ethics 20, 85-92.

Herndon, N. C., J. P. Fraedrich and Q. J. Yeh: 2001, 'An Investigation of Moral Values and the Ethical Content of the Corporate Culture: Taiwanese Versus Us Sales People', Journal of Business Ethics 30, 73-85.

Hoivik, H. V. W.: 2007, 'East Meets West: Tacit Messages About Business Ethics in Stories Told by Chinese Managers', Journal of Business Ethics 74, 457-469.

Huang, L. F. J. and R. S. Snell: 2003, 'Turnaround, Corruption and Mediocrity: Leadership and Governance in Three State Owned Enterprises in Mainland China', Journal of Business Ethics 43, 111-124.

Hung, H.: 2008, 'Normalized Collective Corruption in a Transitional Economy: Small Treasuries in Large Chinese Enterprises', Journal of Business Ethics 79, 69-83.

Ip, P. K.: 2002, 'The Weizhi Group of Xian: A Chinese Virtuous Corporation', Journal of Business Ethics 35, 15-26.

Ip, P. K.: 2008, 'Corporate Social Responsibility and Crony Capitalism in Taiwan', Journal of Business Ethics 79, 167-177.

Islam, M. and M. Gowing: 2003, 'Some Empirical Evidence of Chinese Accounting System and 
Business Management Practices from an Ethical Perspective', Journal of Business Ethics 42, 353-378.

Jakubowski, S. T., P. Chao, S. K. Huh and S. Maheshwari: 2002, 'A Cross-Country Comparison of the Codes of Professional Conduct of Certified/ Chartered Accountants', Journal of Business Ethics 35, 111-129.

Khatri, N. and E. W. K. Tsang: 2003, 'Antecedents and Consequences of Cronyism in Organizations', Journal of Business Ethics 43, 289-303.

Krueger, D. A.: 2008, 'The Ethics of Global Supply Chain in China - Convergence of East and West', Journal of Business Ethics 79, 113-120.

Kumar, K. and M. S. Thibodeaux: 1998, 'Differences in Value Systems of Anglo-American and Far Eastern Students: Effects of American Business Education', Journal of Business Ethics 17, 253-262.

Kuo, F. Y., C. S. Lin and M. H. Hsu: 2007, 'Assessing Gender Differences in Computer Professionals' Self-Regulatory Efficacy Concerning Information Privacy Practices', Journal of Business Ethics 73, 145-160.

Lam, K. C.: 2002, 'A Study of the Ethical Performance of Foreign-Investment Enterprises in the China Labor Market', Journal of Business Ethics 37, 349-365.

Lam, K. C. and B. W. S. Hung: 2005, 'Ethics, Income and Religion', Journal of Business Ethics 61, 199-214.

Lam, K. C. and G. C. Shi: 2008, 'Factors Affecting Ethical Attitudes in Mainland China and Hong Kong', Journal of Business Ethics 77, 463-479.

Lam, K. C. J.: 2003, 'Confucian Business Ethics and the Economy', Journal of Business Ethics 43, 153-162.

Lee, K. H., D. P. McCann and M. A. Ching: 2003, 'Christ and Business Culture: A Study of Christian Executives in Hong Kong', Journal of Business Ethics 43, 103-110.

Lehman, J. A.: 2006, 'Intellectual Property Rights and Chinese Tradition Section: Philosophical Foundations', Journal of Business Ethics 69, 1-9.

Lin, C. P.: 2007, 'To Share or Not to Share: Modeling Tacit Knowledge Sharing, Its Mediators and Antecedents', Journal of Business Ethics 70, 411-428.

Lin, G. T. R. and J. Lin: 2006, 'Ethical Customer Value Creation: Drivers and Barriers', Journal of Business Ethics 67, 93-105.

Lu, L. C., G. M. Rose and J. G. Blodgett: 1999, 'The Effects of Cultural Dimensions on Ethical
Decision Making in Marketing: An Exploratory Study', Journal of Business Ethics 18, 91-105.

Lu, X. H.: 2006, 'On P2p File-Sharing: A Major Problem - a Chinese Perspective', Journal of Business Ethics 63, 63-73.

Majid, A., F. A. Gul and J. S. L. Tsui: 2001, 'An Analysis of Hong Kong Auditors' Perceptions of the Importance of Selected Red Flag Factors in Risk Assessment', Journal of Business Ethics 32, 263-274.

McGee, R. W., S. S. M. Ho and A. Y. S. Li: 2008, 'A Comparative Study on Perceived Ethics of Tax Evasion: Hong Kong vs the United States', Journal of Business Ethics 77, 147-158.

Millington, A., M. Eberhardt and B. Wilkinson: 2005, 'Gift Giving, Guanxi and Illicit Payments in Buyer-Supplier Relations in China: Analyzing the Experience of UK Companies', Journal of Business Ethics 57, 255-268.

Phau, I. and G. Kea: 2007, 'Attitudes of University Students Toward Business Ethics: A Cross-National Investigation of Australia, Singapore and Hong Kong', Journal of Business Ethics 72, 61-75.

Rashid, M. Z. A. and J. A. Ho: 2003, 'Perceptions of Business Ethics in a Multicultural Community: The Case of Malaysia', Journal of Business Ethics 43, 75-87.

Redfern, K. and J. Crawford: 2004, 'An Empirical Investigation of the Ethics Position Questionnaire in the People's Republic of China', Journal of Business Ethics 50, 199-210.

Sarwono, S. S. and R. W. Armstrong: 2001, 'Microcultural Differences and Perceived Ethical Problems: An International Business Perspective', Journal of Business Ethics 30, 41-56.

Selmer, J. and A. S. M. Leung: 2003, 'Are Corporate Career Development Activities Less Available to Female than to Male Expatriates?', Journal of Business Ethics 43, 125-136.

Shafer, W. E., K. Fukukawa and G. M. Lee: 2007, 'Values and the Perceived Importance of Ethics and Social Responsibility: The US Versus China', Journal of Business Ethics 70, 265-284.

Snell, R. S., A. M. K. Chak and J. W. H. Chu: 1999, 'Codes of Ethics in Hong Kong: Their Adoption and Impact in the Run up to the 1997 Transition of Sovereignty to China', Journal of Business Ethics 22, 281-309.

Snell, R. S. and N. C. Herndon: 2004, 'Hong Kong's Code of Ethics Initiative: Some Differences 
Between Theory and Practice', Journal of Business Ethics 51, 75-89.

Steidlmeier, P.: 1999, 'Gift Giving, Bribery and Corruption: Ethical Management of Business Relationships in China', Journal of Business Ethics 20, 121-132.

Su, C. T. and J. E. Littlefield: 2001, 'Entering Guanxi: A Business Ethical Dilemma in Mainland China?', Journal of Business Ethics 33, 199-210.

Su, C. T., R. K. Mitchell and J. Sirgy: 2007, 'Enabling Guanxi Management in China: A Hierarchical Stakeholder Model of Effective Guanxi', Journal of Business Ethics 71, 301-319.

Su, C. T., M. J. Sirgy and J. E. Littlefield: 2003, 'Is Guanxi Orientation Bad, Ethically Speaking? A Study of Chinese Enterprises', Journal of Business Ethics 44, 303-312.

Tam, O. K.: 2002, 'Ethical Issues in the Evolution of Corporate Governance in China', Journal of Business Ethics 37, 303-320.

Tan, D. and R. S. Snell: 2002, 'The Third Eye: Exploring Guanxi and Relational Morality in the Workplace', Journal of Business Ethics 41, 361-384.

Tang, J. H. and C. K. Fam: 2005, 'The Effect of Interpersonal Influence on Softlifting Intention and Behavior', Journal of Business Ethics 56, 149-161.

Tang, T. L. P. and R. K. Chiu: 2003, 'Income, Money Ethic, Pay Satisfaction, Commitment, and Unethical Behavior: Is the Love of Money the Root of Evil for Hong Kong Employees?', Journal of Business Ethics 46, 13-30.

Tsui, J. and C. Windsor: 2001, 'Some CrossCultural Evidence on Ethical Reasoning', Journal of Business Ethics 31, 143-150.

Wang, H. Z.: 2005, 'Asian Transnational Corporations and Labor Rights: Vietnamese Trade Unions in Taiwan-Invested Companies', Journal of Business Ethics 56, 43-53.

Warren, D. E., T. W. Dunfee and N. Li: 2004, 'Social Exchange in China: The Double-Edged Sword of Guanxi', Journal of Business Ethics 55, 355372.

Whitcomb, L. L., C. B. Erdener and C. Li: 1998, 'Business Ethical Values in China and the Us', Journal of Business Ethics 17, 839-852.

Wong, Y. H. and R. Y. K. Chan: 1999, 'Relationship Marketing in China: Guanxi, Favoritism and Adaptation', Journal of Business Ethics 22, 107118.

Woodbine, G. F.: 2004, 'Moral Choice and the Declining Influence of Traditional Value Orientations Within the Financial Sector of a Rapidly Developing Region of the People's Republic of China', Journal of Business Ethics 55, 43-60.

Woodbine, G. F. and D. Taylor: 2006, 'Moral Choice in an Agency Framework: The Search for a Set of Motivational Typologies', Journal of Business Ethics 63, 261-277.

Wu, C. F.: 2001, 'The Study of Global Business Ethics of Taiwanese Enterprises in East Asia: Identifying Taiwanese Enterprises in Mainland China, Vietnam and Indonesia as Targets', Journal of Business Ethics 33, 151-165.

Wu, C. F.: 2002, 'Business Should Be Its Own Therapist: Observing the 'Governance Ethics' of Taiwanese Enterprises', Journal of Business Ethics 40, 363-371.

Wu, C. F.: 2002, 'The Relationship of Ethical Decision-Making to Business Ethics and Performance in Taiwan', Journal of Business Ethics 35, 163-176.

Wu, C. F.: 2003, 'A Study of the Adjustment of Ethical Recognition and Ethical Decision-Making of Managers-to-Be Across the Taiwan Strait Before and After Receiving a Business Ethics Education', Journal of Business Ethics 45, 291-307.

Wu, C. F.: 2004, 'Research on a Typology of Business Ethics Operation Across the Taiwan Strait', Journal of Business Ethics 52, 229-242.

Zhang, Y. and Z. G. Zhang: 2006, 'Guanxi and Organizational Dynamics in China: A Link Between Individual and Organizational Levels', Journal of Business Ethics 67, 375-392.

Zhuang, G. and A. S. L. Tsang: 2008, 'A Study of Ethically Problematic Methods in China with a Broader Concept of Gray-Marketing', Journal of Business Ethics 79, 85-101.

\section{References}

Carroll, A. B.: 1979, 'A Three-Dimensional Conceptual Model of Corporate Social Performance', Academy of Management Review 4(4), 497-505. 
Kohlberg, L.: 1969, 'Stages and Sequences: The Cognitive Development Approach to Socialization', in D. A. Goslin (ed.), Handbook of Socialization Theory and Research (Rand McNally, Chicago, IL), pp. 347480 .

Kohlberg, L.: 1981, Essays on Moral Development: The Philosophy of Moral Development, Vol. 1 (Harper Row, New York).

Maignan, I.: 2001, 'Consumers' Perception of Corporate Social Responsibility: A Cross Cultural Perception', Journal of Business Ethics 30(1), 57-72.

Parker, E.: 2007, 'Made in China', The Wall Street Journal (Eastern edition). New York, N.Y.: July 12, 2007, p. A15.

Rest, J. R., D. Narvaez, S. T. Thoma and M. J. Bebeau: 2000, 'A Neo-Kohlbergian Approach to
Morality Research', Journal of Moral Education 29, 381-396.

Schwartz, S. H.: 1992, 'Universals in the Content and Structure of Values: Theoretical Advances and Empirical Tests in Twenty Countries', Advances in Experimental Social Psychology 25, 1-65.

School of Business, Hong Kong Baptist University, The Wing Lung Bank Building for Business Studies, 34 Renfrew Road, Kowloon Tong, Kowloon, Hong Kong, China E-mail:allankk@hkbu.edu.hk 